\title{
Evaluation of the strength reduction method for US coal mine entry stability analysis
}

\author{
G.S. Esterhuizen National Institute for Occupational Safety and Health, USA
}

T.S. Bajpayee National Institute for Occupational Safety and Health, USA

M.M. Murphy National Institute for Occupational Safety and Health, USA

J.L. Ellenberger National Institute for Occupational Safety and Health, USA

\begin{abstract}
The strength reduction method (SRM) can be used to calculate a stability factor of a proposed excavation through the use of well-calibrated numerical models. The method models the excavation and support system while the rock mass strength is reduced in stages until failure is indicated. The stability factor is expressed as the ratio of the expected rock mass strength to the rock mass strength that results in failure. Using the stability factor, various support alternatives can be compared and the impact of specific changes to the support system can be evaluated. Strength reduction analyses were conducted using calibrated models of coal mine entries in various geological settings. The calculated stability factors were validated against the empirically derived Coal Mine Roof Rating (CMRR) and the Analysis of Roof Bolt Systems (ARBS), which is based on observation and statistical analysis of roofbolt systems in US coal mines. The results showed that the stability factors estimated through the SRM capture the essence of the CMRR, indicating improved stability at higher CMRR values and also replicating details such as the effect of a strong bed in the roof and the effect of a weak overlying bed. A linear relationship was found between the stability factors calculated by the strength reduction method and the ARBS. The calculated stability factors for instrumented field sites fell within the expected range of values based on observed entry stability. It is concluded that the stability factors calculated by the strength reduction method provide a meaningful interpretation of overall excavation stability. The numerical model outputs can be used to evaluate the contribution of support elements, allowing optimisation of the support design.
\end{abstract}

\section{Introduction}

Each year approximately 1,200 non-injury roof falls that occur in underground coal mines in the United States are reported to the Mine Safety and Health Administration (Mine Safety and Health Administration, 2012). These roof falls are reported if they extend above the supported horizon, impede access to the working areas or if ventilation is interrupted. Reported roof falls may include cases of well supported entries, no support, poorly installed support, inadequate design or deteriorated supports. Each fall represents a safety hazard and can be considered to be a failure of the ground support system. The research presented in this paper has the objective to reduce the occurrence of large roof falls in underground coal mines by addressing the support design aspect.

When designing support for an underground excavation, the challenge is to account for the uncertainty in the rock strength, rock loading and support system capacity. An adequate margin of safety is required between the expected loading and the capacity of the support system. The classic safety factor used in engineering design expresses the margin of safety as the ratio of the capacity of a system to the expected loading of the system. However, for underground excavations the safety factor is not easily estimated because the supports are integrated within the rock mass, while the rock mass is considered to be a part of the support system. As a result, the safety factor approach has not found widespread application in underground excavation support design. 
The strength reduction method (Zienkiewicz et al., 1975) is an alternative approach that can be used to quantify the stability of an excavation. The method calculates the factor of safety of an excavation as the ratio of the expected rock strength to the rock strength that would result in failure or collapse of the excavation. This paper discusses the procedures for conducting a strength reduction analysis, how it has been implemented in numerical models of coal mine entries and how the outputs compare to empirical evidence. The paper concludes with two example applications.

\section{The strength reduction method}

The strength reduction method (SRM) was originally developed to provide an alternative method of calculating the stability of rock slopes using numerical models (Zienkiewicz et al., 1975). It has since found application in rock slope design (Lorig and Varona, 2000; Diederichs et al., 2007), but has not been widely used for underground excavation stability analysis.

\subsection{Steps in the analysis}

The SRM is applied by first conducting a stability analysis of an excavation using average rock strength properties. Depending on the outcome, the analysis is repeated using either a decreased or increased strength until the point of collapse is satisfactorily defined. When modelling rock slopes or underground excavations, collapse is indicated by the inability of the model to reach a state of equilibrium after an extended number of solution cycles. Strength adjustments are achieved by simultaneously reducing or increasing the cohesion, tensile strength and the coefficient of friction of the rock matrix and the bedding planes. The safety factor of the system is simply calculated as the inverse of the strength adjustment factor at the point of collapse of the modelled excavation. For example, if collapse occurs when the strength is reduced by a factor of 0.8 , the safety factor would be 1.25 . For slope analysis, the SRM has the advantage that the failure surfaces are not pre-defined, but failure develops in the model as dictated by the stress distribution and the properties of the materials in the rock slope. When applied to underground excavations, failure development is similarly estimated by the rock mass properties, stress field and excavation shape.

\subsection{Entry failure and stability factor}

The state of 'failure' being investigated must be clearly defined when using the SRM. For this study an entry is considered to have failed if roof collapse occurs that exceeds the bolt length, which is included in the definition of a reportable roof fall (Mine Safety and Health Administration, 2012). This definition of entry failure is not to be confused with damage of the rock material around the opening. In many cases, damaged or fractured rock material can exist around an entry while the support system prevents collapse from occurring. In such a case the entry may be considered to be stable in spite of the existence of damaged rock around the excavation.

The term 'stability factor' is used in this paper because it is a ratio of strengths of the rock mass, rather than the ratio of strength to load, as used in the classic safety factor calculation. The stability factor magnitude has a similar interpretation as safety factor magnitudes. A stability factor of 1.0 would indicate that a system is expected to be at the point of failure, while less than 1.0 would indicate the increased likelihood for instability, and greater than 1.0 would indicate increasing likelihood of stability.

\subsection{Implementation of the method}

The FLAC3D (Anon., 2011) finite-difference code was used to conduct the strength reduction analyses. The code is well-suited to modelling the non-linear response of geomaterials, ground support systems and the large strain encountered in underground coal mine excavations.

The strength reduction technique was implemented by running the models in a batch where the outcome of each model is used to estimate the strength reduction of the next model. If the initial model is stable, the strength of the materials is reduced in stages until the model fails. Once a state of failure has been 
achieved, the next strength reduction is selected midway between the previous two strength reduction factors, known as the bisection method. The analyses were halted when the difference between strength reduction factors of two successive runs was less than 0.05 . Typically five or six separate solutions of the model are necessary. Note that the models are recreated and initialised at the start of each solution run.

Failure of the modelled entries was identified by inserting velocity monitoring points within the bolted horizon of the entry roof. Failure or collapse of the roof is indicated if the monitoring points are moving downwards at a constant velocity after an extended number of solution cycles.

\subsection{Adjustments for evaluating coal mine entries}

In underground coal mining situations the floor rocks can sometimes be weaker than the roof rocks. If the rock strength is reduced equally in the roof and floor during an analysis, floor heave may become the ultimate mechanism of instability in the numerical model. The analyses reported here were therefore conducted by only reducing the rock mass strength above the roof-line of the excavation while leaving the coal and floor rocks below the roof-line unadjusted. It is recognised that floor heave may be a contributing factor in roof failure, but was not investigated in this study.

When analysing supported excavations, the support system is included in the models during the stages of strength reduction. There is still some debate about whether the support strength should also be reduced when the rock strength is reduced (Diederichs et al., 2007). In the analyses presented here, the strength of the support system was held constant during the stages of rock strength reduction. The argument for this approach is that if the performance of a given support system is being evaluated then its strength remains constant during the evaluation.

The focus of the method is on roof falls associated with low strength or overstressed ground. Gravity driven falls related to individual geological structures, such as large slips or faults, are not included. Smaller skin falls that occur between supports are also excluded because they do not meet the 'failure' definition as described above.

\section{$3 \quad$ Numerical model development}

The bedded strata found in coal mines were modelled using the strain-softening ubiquitous joint constitutive model available in FLAC3D. The constitutive model is based on the Coulomb criterion in which the friction angle, tensile strength and cohesion are used to specify the rock strength. The strength parameters of the rock matrix and the bedding planes are specified separately. The approach closely resembles the 'synthetic rock mass' concept (Pierce et al., 2007) in which the rock matrix and the discontinuities are modelled separately. The model inputs and results were initially calibrated against field instrumentation studies (Esterhuizen, 2012). The calibration studies included rock deformation, bolt loads and entry stability analysis in a variety of geological conditions encountered within the US coal regions. During the calibration stage, a systematic procedure for obtaining model inputs from field data was developed based on the Coal Mine Roof Rating (CMRR) (Molinda and Mark, 1994; Molinda and Mark, 1996). Using this approach, the rock mass is divided into units, each unit having similar strength properties. The procedures can be used by support designers to create numerical models in the absence of detailed laboratory test results.

\subsection{Model layout}

The models simulated cross-sections through coal mine entries in various geological settings. The model boundaries were located at least three times the entry span away from the edges of the entry, and extended about $20 \mathrm{~m}$ above and $10 \mathrm{~m}$ below the entries. The outer boundaries of the models were fixed against normal displacement, while allowing displacement to take place along the boundary surface (i.e. 'roller boundaries'). The models were typically $1.2 \mathrm{~m}$ wide in the direction perpendicular to the section, which represents the typical slice of rock supported by a single row of bolts. The element side dimensions were approximately $30 \mathrm{~cm}$ in the vicinity of the entry and were increased up to about $1.2 \mathrm{~m}$ at the 
extremities of the model. An attempt was made to maintain a constant element edge length of $30 \mathrm{~cm}$ in the areas where failure is expected to develop. However, when modelling geologic beds of variable thickness, the vertical dimension of the elements was necessarily adjusted to match the actual geology, with a minimum of $15 \mathrm{~cm}$.

\subsection{Rock matrix strength}

The uniaxial compressive strength (UCS) of the rock matrix is used as a starting point for estimating the triaxial strength parameters. The results of triaxial strength tests were supplemented by published data and used to develop the cohesion, friction and tensile strength parameters for a variety of coal measure rocks. The cohesion of the rock matrix was reduced by a factor of 0.58 in the models to account for the difference between the strength of laboratory-scale and field-scale rock samples (Hoek and Brown, 1980; Gale, 1999). Post-peak strength reduction was modelled by allowing the cohesion to decrease with increasing plastic strain, while maintaining a constant friction angle. For the rock types the cohesion was reduced to $10 \%$ of its original value over $1 \%$ plastic strain. Residual cohesion was arbitrarily set at $1.0 \mathrm{kPa}$ after $5 \%$ plastic strain.

The strength of bedded rocks can be highly anisotropic, and this phenomenon has an especially important impact on roof stability when subject to the high horizontal stress found in many US coal mines (Mark et al., 2002; Esterhuizen and Bajpayee, 2012). Strength anisotropy was accounted for in the models as based on the intensity and strength of the bedding planes (Esterhuizen, 2012). A small script code was written in FLAC3D that reduces the cohesion of the rock when the major principal stress is oriented within $30^{\circ}$ of the bedding surface.

\subsection{Bedding plane strength}

The bedding planes within a unit of rock are modelled as a set of horizontal ubiquitous joints in FLAC3D. Strength estimates for the bedding planes were based on the results of limited laboratory tests on angled drill core (Gale et al., 2004), and were expanded using the discontinuity strength rating (DSR) in the CMRR. The DSR describes both the bedding cohesion and roughness which are rated using field techniques described by Molinda and Mark (1994). The DSR rating varies from a minimum value of 10 units for slickensided planar bedding planes, to a maximum value of 35 units for strong-jagged surfaces. The relationships that were used to estimate the bedding cohesion $\left(C_{j}\right)$ and friction angle $\left(F_{j}\right)$ for modelling purposes were as follows:

$$
\begin{gathered}
C_{j}=C_{m} \times 4 \times 10^{-6} \times D S R^{3.6141} \\
F_{j}=F_{m}-(0.34 \times D S R-13.0)
\end{gathered}
$$

Where:

$C_{m}=$ cohesion of the rock matrix.

$F_{m} \quad=\quad$ friction angle of the rock matrix in degrees.

$F_{j}$ was limited to the range of $F_{m}$ to $\left(F_{m}-5^{\circ}\right)$.

The bedding friction angle and cohesion values were held constant during plastic yield. The models were run in the small-strain mode to alleviate the formation of unrealistic kink-bands in the ubiquitous joint materials.

\subsection{Interfaces between rock units}

The interfaces between different rock units were explicitly modelled using the interface elements available in FLAC3D. The cohesion and friction angles of the rock interfaces were estimated using the DSR values of the contacts, as described above. The presence of explicit interfaces allows sliding, separation and closure between the different rock units to be modelled. 


\subsection{Modelling of support units}

The FLAC3D software has a variety of built-in support types that are modelled using finite elements. The various types of grouted bolts and cable bolts evaluated in this study were modelled using the built-in 'pile' support units. These support units are effective for modelling the response of the grout, the steel and the interface between the grout and the rock (Tulu et al., 2012). The boundary conditions caused the model to effectively simulate a long entry excavation with repeating rows of supports. Strength parameters for the grout-rock interface were based on the results of published field and laboratory tests (Zipf, 2006).

\subsection{Field stress modelling}

The vertical stress in the models was simply based on the depth of cover and the average density of the overlying rocks. The major horizontal stress in US coal regions appears to be closely related to present day tectonic loading (Mark and Gadde, 2008) and can be two to three times the vertical stress. The tectonic component of the horizontal stress is closely related to the elastic modulus of the individual rock units (Mark and Gadde, 2008; Dolinar, 2003). The models accounted for the elastic modulus related variation of the horizontal stress.

\section{$4 \quad$ Evaluation of strength reduction method results}

The SRM was used to calculate stability factors for coal mine entries in a variety of geotechnical conditions. The intention was to assess whether the calculated stability factors followed the same trends as those predicted by empirical methods such as the CMRR and the empirically derived Analysis of Roof Bolt Systems (ARBS) (Mark et al., 2001; Mark, 2000). In addition, a number of monitored field experiments were analysed to correlate the calculated stability factors with observed entry performance.

\subsection{Comparison to the Coal Mine Roof Rating}

The CMRR (Molinda and Mark, 1996) was developed specifically to quantify the strength of bedded strata within the bolted horizon of an excavation. The objective was to determine whether the stability factors estimated by the SRM would follow the same trends as the CMRR for a variety of geological and stress conditions. A series of five different geological settings were created to represent conditions that may be encountered in typical underground coal mines, shown in Table 1. In each model the roof consisted of $0.6 \mathrm{~m}$ thick units of bedded rocks separated by discretely modelled interfaces. The properties of the units within the first $3 \mathrm{~m}$ of the roof of the entry were as follows, using CMRR-based descriptions and unit ratings.

- Very weak shale: UCS $20 \mathrm{MPa}$, contains planar slickensided bedding joints spaced $25 \mathrm{~mm}$ apart. Unit rating is 29 .

- Weak shale: UCS $30 \mathrm{MPa}$, contains very weak planar beds spaced $75 \mathrm{~mm}$ apart. Unit rating is 37 .

- Moderate shale: UCS $40 \mathrm{MPa}$, with weak planar bedding spaced $150 \mathrm{~mm}$ apart. Unit rating is 44 .

A numerical model was created of each setting and model inputs were created using the procedures described in Section 2 of this paper. The SRM was used to estimate the stability factor for each geological setting at 100, 200 and $300 \mathrm{~m}$ depth of cover. Three horizontal stress scenarios were selected to represent unfavourable, moderate and favourable stress conditions that are encountered in US coal mines. The three stress scenarios are described as follows:

- Stress A: Unfavourable stress conditions. The entry is oriented perpendicular to the major horizontal stress which is 2.0 times the vertical stress.

- Stress B: Moderate stress conditions. The entry is oriented parallel to the major horizontal stress, which is 2.0 times the vertical stress. 
- Stress C: Favourable stress conditions. The entry is oriented perpendicular to the major horizontal stress which is equal to the vertical stress.

The minor horizontal stress was set at 0.6 times the vertical stress.

The analyses were carried out with the commonly used $1.8 \mathrm{~m}$ long fully grouted supports, and without support. The CMRR was calculated for each scenario, based on the support length of $1.8 \mathrm{~m}$. Note that Scenario 4 was designed to include the 'strong bed adjustment' and Scenario 5 the 'surcharge' adjustment in the CMRR. The surcharge adjustment accounts for the presence of a weak layer above the bolted horizon that may impose a surcharge load. An example of the results for entries at $200 \mathrm{~m}$ depth of cover in unfavourable stress conditions are shown in Table 1. The CMRR and stability factor (SF) values for this case are also shown graphically in Figure 1.

Table 1 Geological scenarios, CMRR ratings and SF results for $200 \mathrm{~m}$ depth of cover

\begin{tabular}{|c|c|c|c|c|c|}
\hline \multicolumn{2}{|c|}{ Scenario } & \multirow{2}{*}{$\begin{array}{c}\text { Roof Composition } \\
\text { Weak shale }\end{array}$} & \multirow{2}{*}{$\begin{array}{c}\text { CMRR } \\
37.0\end{array}$} & \multirow{2}{*}{$\begin{array}{c}\text { SF } \\
\text { Unsupported } \\
0.93\end{array}$} & \multirow{2}{*}{$\begin{array}{c}\begin{array}{c}\text { SF } \\
\text { Supported }\end{array} \\
1.20\end{array}$} \\
\hline 1) & Weak roof & & & & \\
\hline 2) & Moderate roof & Moderate shale & 44.0 & 1.29 & 2.08 \\
\hline 3) & Increasing strength & $\begin{array}{l}\text { Weak shale } 1.2 \mathrm{~m} \text { thick overlain by } \\
\text { moderate shale }\end{array}$ & 40.8 & 0.96 & 1.34 \\
\hline 4) & Weak bed & $\begin{array}{l}\text { Moderate shale roof with single } \\
\text { very weak shale unit at } 1.8-2.4 \mathrm{~m}\end{array}$ & 41.4 & 1.15 & 1.52 \\
\hline 5) & Strong bed & $\begin{array}{l}\text { Weak shale with a single moderate } \\
\text { shale unit at } 1.2-1.8 \mathrm{~m}\end{array}$ & 39.2 & 0.90 & 1.24 \\
\hline
\end{tabular}

The results show that the CMRR and SF values follow similar trends. Both methods show a large difference in expected stability between the weak roof Scenario 1 and Scenario 2 where the roof consists of stronger rocks. Comparing Scenario 1 to Scenario 3 shows that the benefit of anchoring a weak layer to a stronger layer is clearly captured by both approaches. Interestingly, the SRM shows only a small difference between these scenarios when there is no support, which is logical, since the entry roof cannot derive a benefit from the stronger upper roof if it is not anchored to it.

The 'strong bed adjustment' in the CMRR is demonstrated by comparing Scenario 1 to Scenario 5. The CMRR rating increases from 37.0 to 39.2 because of the presence of the stronger layer in the otherwise weak roof. The SF for the unsupported entry actually does go down slightly, which is not unexpected, since there are no supports to take advantage of the strong bed. However, when supports are installed, the SF increases from 1.20 to 1.24 - a smaller increase than predicted by the CMRR, but following the same trend.

Finally, the 'surcharge adjustment' in the CMRR, where the rating is reduced if a stronger unit is overlain by a weaker unit, is demonstrated by comparing Scenario 2 to Scenario 4 . Here the CMRR decreases from 44.0 to 41.4 and the SF reduces in a similar manner for both the supported and unsupported cases, showing that the surcharge is equally unfavourable whether support is used or not. 


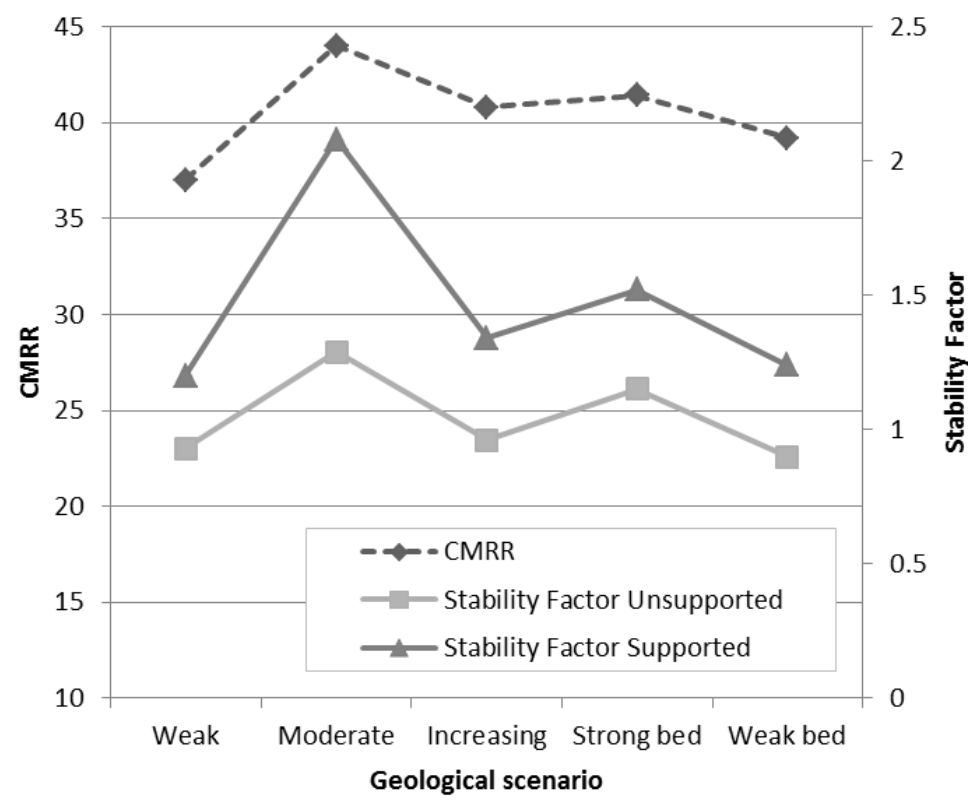

Figure 1 Comparison of CMRR values and SF calculated using the SRM for entries at 200 m depth of cover

The relationship between entry stability factors and CMRR at various depths of cover is shown in Figure 2 . In this figure, the results for the three horizontal stress scenarios are averaged and presented as a single result for each CMRR value. The strong correlation between CMRR and the results of the SRM can be seen to apply for the depths considered. The effect of depth on entry stability is clearly seen as the stability factors decrease with increasing depth. The figure also shows that the range of stability factors decreases at increasing depth, as the higher stress at greater depth becomes more dominant.

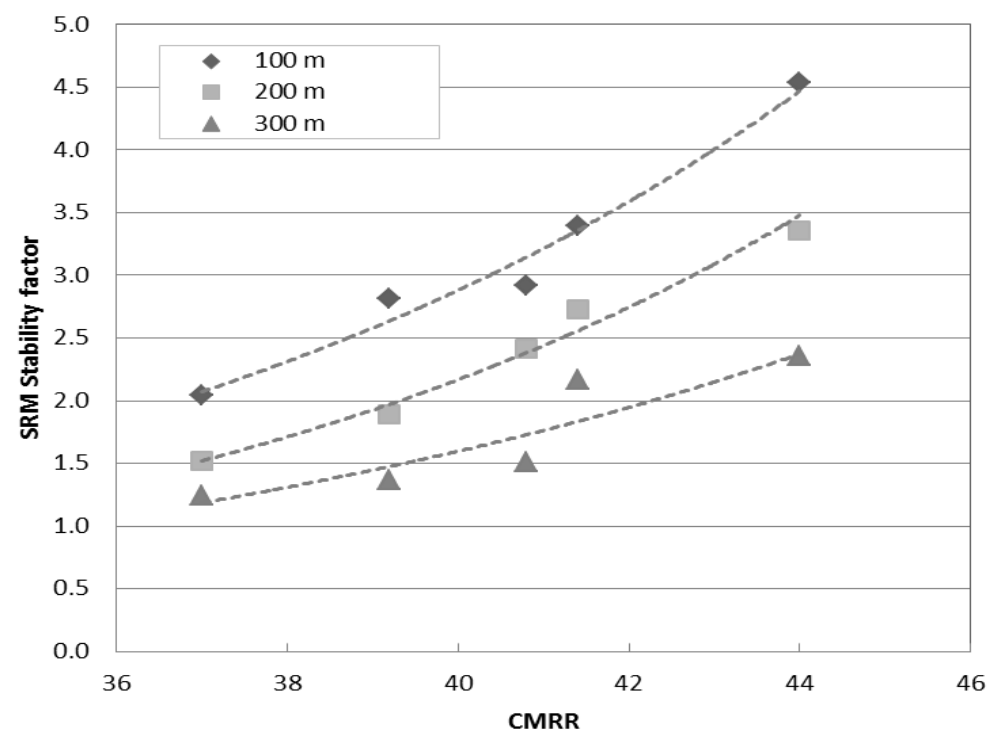

\section{Figure 2 Relationship between entry SF, calculated using the SRM and the CMRR for various depths of cover}

This evaluation has shown that the SRM provides results that follow the trends seen in the empirically based CMRR ratings. The method is able to recognise the advantage of a strong bed in the bolted horizon and also the weakening effect of surcharge from weak layers. The depth effect on entry stability is also clearly demonstrated in the results. 


\subsection{Comparison to ARBS empirical design recommendations}

The Analysis of Roof Bolt Systems (ARBS) method (Mark et al., 2001; Mark, 2000) was developed through statistical analysis of roof falls at 37 coal mines (Molinda et al., 2000). A relationship between the CMRR and the support intensity was identified for use in support design. The support intensity is expressed by an index parameter called PRSUP which combines the bolt length, spacing, capacity and entry width into a single parameter. A discriminant equation was developed that relates the PRSUP for satisfactory support performance to the CMRR. For the purpose of this study, it was assumed that the PRSUP determined by the discriminant equation represents a stability factor of 1.0.

For comparison to the SRM, the ARBS method was used to evaluate the stability of supported entries located in the five geological scenarios listed in Table 3. Entries $6 \mathrm{~m}$ wide were evaluated at depths of $100 \mathrm{~m}, 200 \mathrm{~m}$, and $300 \mathrm{~m}$, supported by fully grouted $160 \mathrm{kN}$ capacity bolts, $1.8 \mathrm{~m}$ long. There were five bolts in a row and the row spacing was $1.2 \mathrm{~m}$. The PRSUP for this support system is calculated to be 13.5. An 'ARBS stability factor' was calculated for each scenario as the ratio of the PRSUP of the installed support system to the PRSUP for a stability factor of 1.0.

The SRM was used to simulate entries in the same geological scenarios and with the same support system as described above. The ARBS does not explicitly evaluate the horizontal stress and it was decided to conduct the strength reduction analyses for the three stress scenarios described in Section 4.1, which represent the range of horizontal stress conditions in US coal mines. The stability factor results for the three stress conditions were averaged for comparison to the ARBS results. Table 2 summarises the results of the $200 \mathrm{~m}$ depth case, which show that a relatively large range of stability factors are obtained for the various horizontal stress scenarios. This is not unexpected, because experience has shown that the horizontal stress magnitude has a significant effect on entry stability (Mark, 2000; Mark and Mucho, 1994). The ARBS design equation does not discriminate between various horizontal stress scenarios, but represents the 'average' stress conditions. The results of SRM were therefore also averaged. Figure 3 presents the correlation between the stability factors of the two methods at 100, 200 and $300 \mathrm{~m}$ depth of cover. The excellent correlation between the results of the statistically based ARBS method and the SRM for this wide ranging set of conditions further confirms the validity of the SRM.

Table 2 Example of SF results using the ARBS method and the SRM. Results for $200 \mathrm{~m}$ depth of cover

\begin{tabular}{llcccccc}
\hline Scenario & CMRR & $\begin{array}{c}\text { Required } \\
\text { PRSUP For } \\
\text { SF }=1.0\end{array}$ & $\begin{array}{c}\text { SF } \\
\text { ARBS }\end{array}$ & $\begin{array}{c}\text { SF } \\
\text { SRM } \\
\text { (Stress A) }\end{array}$ & $\begin{array}{c}\text { SF } \\
\text { SRM } \\
\text { (Stress B) }\end{array}$ & $\begin{array}{c}\text { SF } \\
\text { SRM } \\
\text { (Stress C) }\end{array}$ & $\begin{array}{c}\text { Average } \\
\text { SF }\end{array}$ \\
\hline SRM
\end{tabular}




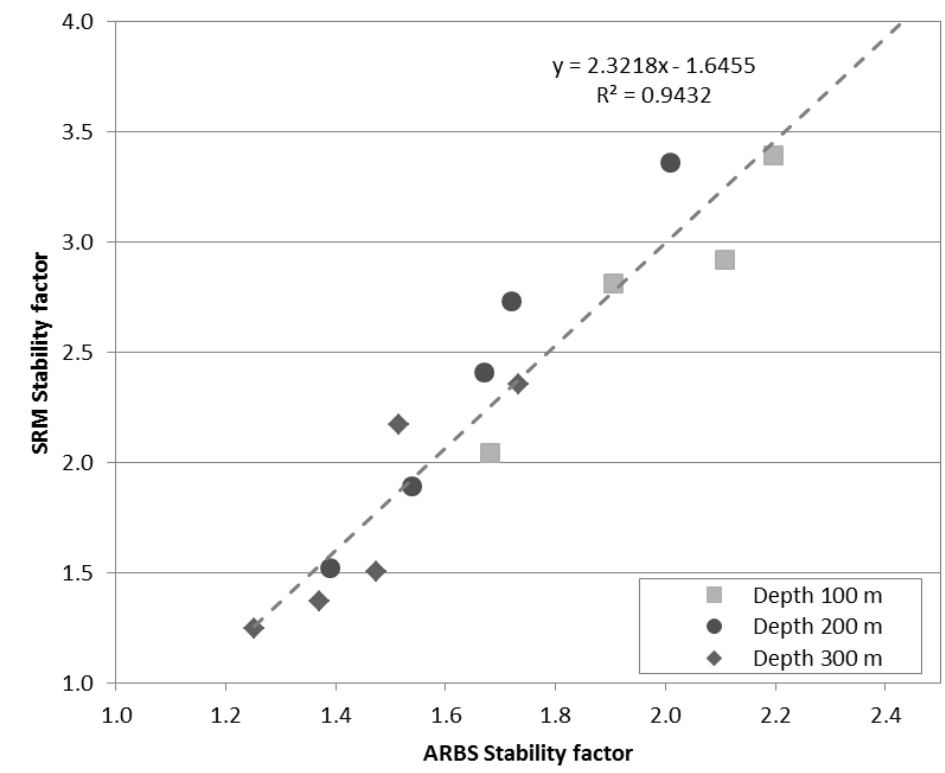

Figure 3 Comparison of SF calculated using the ARBS empirical method and the SRM

\subsection{Assessment of stability factors at experimental sites}

Three experimental field sites were selected for analysis because the results of rock strength test, deformation monitoring and support response were reasonably complete at each site. The available data were used to develop numerical models of the sites using the procedures listed in section 2 of this paper. Stability factors were calculated for each field site using the SRM. The stability factors were calculated with and without support so that the impact of the support system on the stability of the entry could be demonstrated. Details of each site and numerical modelling parameters are given in Esterhuizen (2012). Table 3 presents a summary of the stability factor results. The geotechnical conditions at each site and the stability factor results are discussed below.

\section{Table 3 Calculated stability factors at monitored field sites}

\begin{tabular}{ccc}
\hline Site & Scenario & Stability Factor \\
\hline A & No support & 1.31 \\
& Primary support, $2.4 \mathrm{~m}$ bolts & 2.54 \\
& $2.4 \mathrm{~m}$ bolts and 3.6 m cable support & 2.94 \\
B & No support & 1.20 \\
& Primary support, 1.8 m bolts & 1.78 \\
C & No support & 1.42 \\
& Supported 1.8 m bolts 3.6 m cables & 2.53 \\
\hline
\end{tabular}

Site A: The experimental site was located in the Pittsburgh coal bed under a relatively weak shale roof with coal stringers at $180 \mathrm{~m}$ depth of cover (Oyler et al., 2004). The UCS of the shale in the immediate roof was approximately 20 to $25 \mathrm{MPa}$ increasing to $40 \mathrm{MPa}$ in the bolted horizon. The entry was selected for detailed stress and deformation monitoring because it was expected that the entry would be subject to significant horizontal stresses as a second longwall face approached and passed by. The entry was supported by $2.4 \mathrm{~m}$ grouted bolts and $3.6 \mathrm{~m}$ long cable bolts. Figure 4 shows an example of the model response indicating roof deformation, rock damage and the outline of the collapsing roof. Referring to Table 3 the stability factor for this entry is 1.31 if no support is used. This seems to indicate that temporary stability can be achieved. At this mine temporary stability of the entries is achieved for one or two shifts with only side bolt support, 
before the centre bolt is installed. The $2.4 \mathrm{~m}$ bolts increase the stability factor to 2.54 , indicating that the bolts have a significant effect on stability. The cable bolts result in a further increase in the stability factor to 2.94. The high stability factor under development conditions is not surprising, because the support was designed to withstand extreme loading at the longwall tailgate. The reduced entry width, compared to the other cases evaluated, is also a contributing factor.

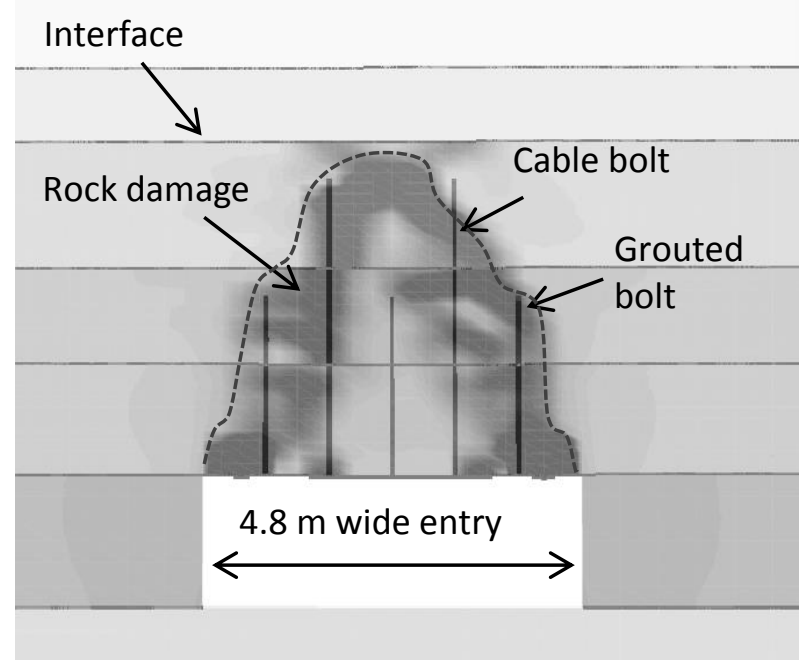

Figure 4 Numerical model results showing failure of an entry supported by $2.4 \mathrm{~m}$ grouted bolts and $3.6 \mathrm{~m}$ cable bolts in a high horizontal stress field. Shading indicates rock damage (plastic strain). The dotted line indicates the collapsing section of the roof

Site B: Three entries were monitored in the Danville No. 7 coal bed, located under a thick weak shale roof in the Illinois basin (Spearing et al., 2011). The strength of the roof shale was in the range of 25 to $30 \mathrm{MPa}$ in the bolted horizon. The entry was located at a depth of cover of approximately $100 \mathrm{~m}$ and was supported by five $1.8 \mathrm{~m}$ long grouted bolts in rows $1.2 \mathrm{~m}$ apart, shown in Figure 5 . The entry was subject only to the stress changes normally encountered during room-and-pillar mining.

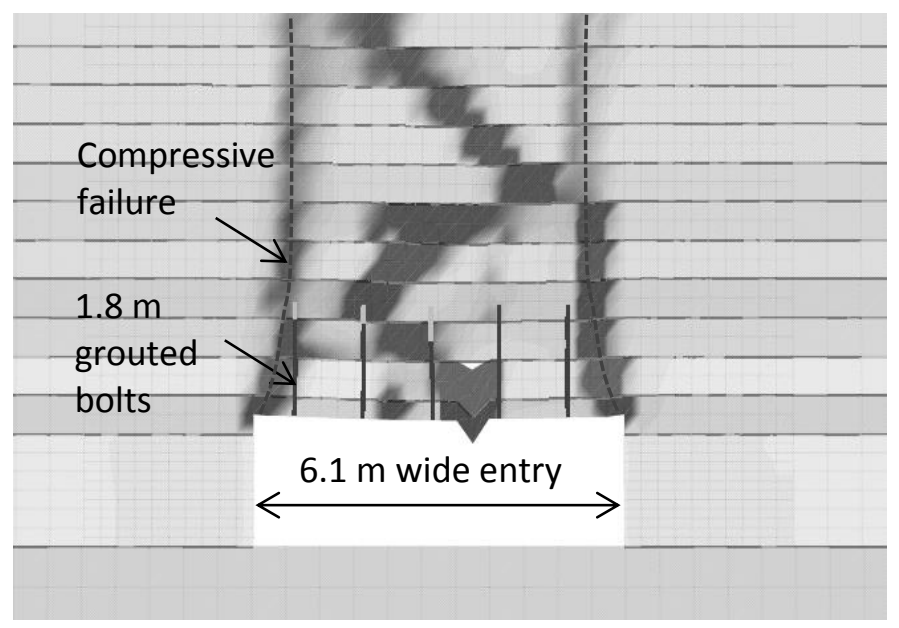

Figure 5 Numerical model results showing failure of an entry supported by $1.8 \mathrm{~m}$ grouted bolts in weak bedded shale rocks. Shading indicates rock damage (plastic strain). The lighter shaded section of the bolts indicates grout yielding in shear. The roof between the two dotted lines is collapsing

Figure 5 shows the response of the model at the start of roof collapse. In this model the relatively weak shale fails by crushing near the excavation corners, followed by cantilever action which progressively develops upwards resulting in chimney-type caving of the roof. The supports are encapsulated within the 
caving rock. The unsupported entry has a low SF of 1.20 which indicates that it is near the limit of stability. At this mine entries are advanced $6 \mathrm{~m}$ before support is installed, indicating that temporary stability can be achieved at this low stability factor. The grouted bolt supports increase the stability factor to 1.78 , indicating that the bolts are effective in increasing the stability. Interestingly, the entry stability factor is lower than site A with primary support, possibly because the grouted bolts at site A were able to anchor in stronger shale.

Site C: A deep cover case in Colorado at a depth of approximately $600 \mathrm{~m}$ under a relatively strong shale roof overlain by strong sandstone (Lawson et al., 2012). Entry and pillar response was monitored at four locations. At one of these locations the shale UCS varied between 36 and $55 \mathrm{MPa}$ and the sandstone UCS was approximately $150 \mathrm{MPa}$, located about $3.0 \mathrm{~m}$ above the entry roof. The support system consisted of $1.8 \mathrm{~m}$ fully-grouted rockbolts supplemented by $3.6 \mathrm{~m}$ partially grouted cable bolts. Steel straps and mesh were used to provide additional area support. Figure 6 shows the results of one of the models after roof collapse has started, indicating that the grouted bolts and the central cable bolt are yielding. The rock damage extends beyond the lateral limits of the entry because the absence of horizontal stress adjacent to the failed entry roof results in a near uniaxial loading condition, which exceeds the UCS of the shale and coal strata adjacent to the entry.

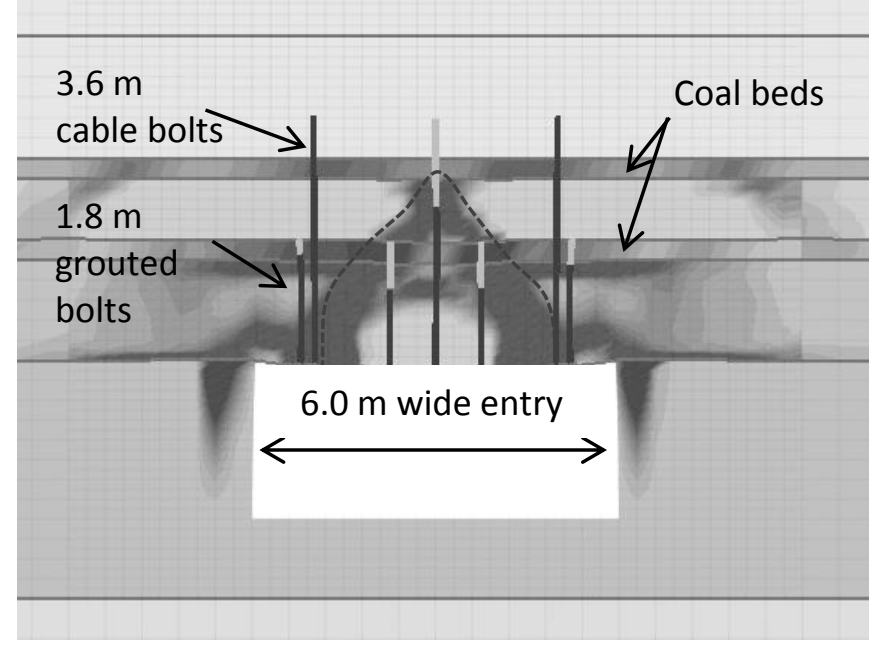

\section{Figure 6 Numerical model results showing failure of an entry supported by $1.8 \mathrm{~m}$ grouted bolts and $3.6 \mathrm{~m}$ cable bolts in strong shale at a depth of $600 \mathrm{~m}$. Shading indicates rock damage (plastic strain). The lighter shaded section of the bolts indicates grout yielding in shear. The dotted line indicates the collapsing section of the roof}

At Site $C$ the stronger shale roof provides as relatively high stability factor of 1.42 without support. Grouted bolts and supplementary cable bolts were installed to accommodate the elevated loading during longwall extraction. When the cable bolts are able to anchor in the strong overlying sandstone, the stability factor increases to 2.53 . The roof ultimately collapses when the modelled rock strength is reduced sufficiently for shear failure to develop up to the upper coal bed, just below the strong sandstone. The central cable bolt carries the majority of the load and starts to pull out of the grout which results in collapse of the central section of the roof.

The field sites provided an opportunity to evaluate the SRM against monitored case histories. The resulting SF fell within the range of values that would be considered reasonable in terms of the interpretation of safety or stability factors in engineering practice (Hoek, 1991; Harr, 1987). The results showed that entries with calculated stability factors between approximately 1.0 and 1.4 are able to remain stable for one or two shifts prior to installation of the primary supports. Supported entries had stability factors in the range of 1.6 to 3.0. Higher stability factors can be achieved with the installation of cable bolts that anchor in stronger strata. 


\section{$5 \quad$ Conclusions}

The results of this study show that the SRM can be used to estimate realistic stability factors against largescale collapse of the supported roof in coal mine entries. A prerequisite for the successful implementation of the method is well-calibrated numerical models that capture the significant mechanisms of rock failure and the response of the support system to the failing rock mass. A procedure was developed to obtain consistent model input parameters from the CMRR classification. The studies presented in this paper demonstrated that:

- The stability factors produced by the SRM closely follow the rating values of the CMRR when modelling various combinations of roof layers. The empirical adjustments to the CMRR such as the 'strong bed adjustment' and the adjustment for 'surcharge' are clearly identifiable in the results of the SRM.

- A linear relationship was found between the stability factors calculated by the SRM and those calculated by the empirically derived ARBS support analysis method for a variety of geological scenarios, field stress conditions, and depths of cover.

- The SRM can be used to evaluate the stability of unsupported entries, which may prove to be useful as an indicator of temporary stability prior to support installation.

- Studies of well-documented field monitoring sites demonstrated that the SRM produces reasonable stability factor values. For the cases evaluated, stability factors of the unsupported entries of between 1.2 and 1.5 seemed to indicate that temporary stability can be achieved prior to support installation. Supported entries had stability factors in the range of 1.6 to 3.0. Further work is recommended to better establish the relationship between stability factors and design.

- Careful evaluation of the model results can assist in understanding the modes of failure and may indicate the best route towards improving the support system.

The SRM has potential to be used as a support design tool, allowing designers to compare and evaluate different support alternatives in a realistic manner. The approach presented in this paper focusses on largescale collapse of the entry roof only. Smaller-scale falls between support units or failures caused by individual geological structures are excluded from this approach.

\section{Disclaimer}

The findings and conclusions in this paper are those of the authors and do not necessarily represent the views of the National Institute for Occupational Safety and Health. Mention of company names, products, or software does not constitute endorsement by NIOSH.

\section{References}

Anon. (2011) FLAC3D Fast Lagrangian Analysis of Continua in 3 Dimensions, Itasca Consulting Group, Minneapolis, MN.

Diederichs, M.S., Lato, M., Hammah, R. and Quinn, P. (2007) Shear Strength Reduction (SSR) approach for slope stability analyses, in Proceedings 1st Canada-US Rock Mechanics Symposium, E. Eberhardt, D. Stead and T. Morrison (eds), 27-31 May 2007, Vancouver, Canada, Taylor \& Francis, London, pp. 319-327.

Dolinar, D. (2003) Variation of Horizontal Stresses and Strains in Mines in Bedded Deposits in the Eastern and Midwestern United States, in Proceedings 22nd International Conference on Ground Control in Mining, S.S. Peng, C. Mark, A.W. Khair, and K. Heasley (eds), 6-7 August 2003, Morgantown, USA, pp. 178-185.

Esterhuizen, G.S. (2012) A Stability factor for Supported Mine Entries Based on Numerical Model Analysis, in Proceedings 31st International Conference on Ground Control in Mining, T. Barczak, S. Tadolini, D. Opfer, M. Thompson, D. Claudhill, B. Warnick and S.S. Peng (eds), 31 July to 2 August 2012, Morgantown, USA, 9 p.

Esterhuizen, G.S. and Bajpayee, T.S. (2012) Horizontal stress related failure in bedded mine roofs-insight from field observations and numerical models, in Proceedings 46th US Rock Mechanics/Geomechanics Symposium, A. Bobet (ed), 24-27 June 2012, Chicaco, USA, Paper No. 137, $10 \mathrm{p}$.

Gale, W.J. (1999) Experience of Field Measurement and Computer Simulation Methods of Pillar Design, in Proceedings Second International Workshop on Coal Pillar Mechanics and Design, J.M. Galvin, B. Hebblewhite and M.D. Salamon, June 1999, 
Pittsburgh, USA, Department of Health and Human Services, National Institute for Occupational Safety and Health, IC 9448, pp. 49-61.

Gale, W.J., Mark, C., Olyer, D. and Chen, J. (2004) Computer Simulation of Ground Behaviour and Rock Bolt Interaction at Emerald Mine, in Proceedings of the 23rd International Conference on Ground Control in Mining, S.S. Peng, C. Mark, G. Finfinger, S. Tadolini, A.W. Khair and K. Heasley (eds), 3-5 August 2004, Morgantown, USA, pp. 27-34.

Harr, M.E. (1987) Reliability Based Design in Civil Engineering, McGraw Hill, 290 p.

Hoek, E. (1991) When is a Design in Rock Engineering Acceptable? Leopold Muller Lecture, in Proceedings 7th International Congress on Rock Mechanics, W. Wittke (ed), 16-20 September 1991, Aachen, Germany, Balkema, Rotterdam, pp 1,4851,497 .

Hoek, E. and Brown, E.T. (1980) Underground Excavations in Rock, Institute of Mining and Metallurgy, London, 527 p.

Lawson, H., Zahl, E. and Whyatt, J. (2012) Ground Condition Mapping: A Case Study, in Proceedings 2012 SME Annual Meeting, 19-22 February 2012, Seattle, USA, Society for Mining, Metallurgy, and Exploration, Inc., Littleton, USA, Preprint, 9 p.

Lorig, L. and Varona, P. (2000) Practical Slope Stability Analysis using Finite-Difference Codes, Slope Stability in Surface Mining, W.A. Hustrulid, M.K. Mc Carter and D.J.A. van Zyl (eds), Society for Mining Metallurgy and Exploration Inc., Littleton, USA, pp. 115-124.

Mark, C. and Gadde, M. (2008) Global Trends in Coal Mine Horizontal Stress Measurements, in Proceedings 27th International Conference on Ground Control in Mining, S.S. Peng, C. Mark, G. Finfinger, S. Tadolini, A.W. Khair, K. Heasley and Y. Luo (eds), 29-31 July, Morgantown, USA, pp. 319-331.

Mark, C., Molinda, G.M. and Barton, T.M. (2002) New Developments with the Coal Mine Roof Rating, in Proceedings 21st International Conference on Ground Control in Mining, S.S. Peng, C. Mark, A.W. Khair and K. Heasley (eds), 6-8 August 2002, Morgantown, USA, pp. 294-301.

Mark, C., Molinda, G.M. and Dolinar, D.R. (2001) Analysis of Roof Bolt Systems, in Proceedings 20th International Conference on Ground Control in Mining, S.S. Peng, C. Mark and A.W. Khair (eds), 7-9 August 2001, WV Univ., Morgantown, USA, pp. 218-225.

Mark, C. (2000) Design of Roof Bolt Systems, in New Technology for Coal Mine Roof Support, NIOSH Open Industry Briefing, C. Mark, D.R. Dolinar and R. Tuchman (eds), Department of Health and Human Services, National Institute for Occupational Safety and Health, IC 9453, 2000, pp. 111-132.

Mark, C. and Mucho, T.P. (1994) Longwall Mine Design for Control of Horizontal Stress, in Proceedings New Technology for Longwall Ground Control, U.S. Bureau of Mines Technology Transfer Seminar, Special Publication 01-94,1994, 12 April and 10 May 1994, Washington and Denver, USA, pp. 53-76.

Mine Safety \& Health Administration (MSHA) (2012) US Department of Labor, Arlington, VA, USA, viewed 13 March 2013, http://www.msha.gov/stats/ statinfo.htm.

Molinda, G.M., Mark, C. and Dolinar, D.R. (2000) Assessing Coal Mine Roof Stability through Roof Fall Analysis, in New Technology for Coal Mine Roof Support NIOSH Open Industry Briefing, C. Mark, D.R. Dolinar, and R. Tuchman (eds), Department of Health and Human Services, National Institute for Occupational Safety and Health, IC 9453, 2000, pp. 53-72.

Molinda, G.M. and Mark, C. (1996) Rating the Strength of Coal Mine Roof Rocks, U.S. Department of the Interior, Bureau of Mines, Pittsburgh, IC $9444.36 \mathrm{p}$.

Molinda, G.M. and Mark, C. (1994) Coal Mine Roof Rating (CMRR): A Practical Rock Mass Rating for Coal Mines, Pittsburgh, Pennsylvania, U.S. Department of the Interior, Bureau of Mines, IC 9387, 83 p.

Oyler, D.C., Mark, C., Gale, W.J. and Chen, J. (2004) Performance of Roof Support Under High Stress in a U.S. Coal Mine, SME preprint 04-135, Society for Mining, Metallurgy, and Exploration, Inc., Littleton, $7 \mathrm{p}$.

Pierce, M., Mas Ivars, D., Cundall, P. and Potyondy, D. (2007) A synthetic rock mass model for jointed rock, in Proceedings 1 st Canada-US Rock Mechanics Symposium, E. Eberhardt, D. Stead and T. Morrison (eds), 27-31 May 2007, Vancouver, Canada, Taylor \& Francis, London, pp. 341-349.

Spearing, A.J.S. and Gadde, M. (2011) Improving underground safety by understanding the interaction between primary rock bolts and the immediate roof strata, Final Report (Oct. 2011), NIOSH Contract No. 200-2009-32518 (2009), 283 p.

Tulu, I.B., Esterhuizen, G.S. and Heasley, K. (2012) Calibration of FLAC3D to Simulate the Shear Resistance of Fully Grouted Rock Bolts, in Proceedings 46th US Rock Mechanics/Geomechanics Symposium, A. Bobet (ed), 24-27 June 2012, Chicaco, USA, $11 \mathrm{p}$.

Zienkiewicz, O.C., Humpheson, C. and Lewis, R.W. (1975) Associated and Non-Associated Visco-Plasticity and Plasticity in Soil Mechanics, Geotechnique, Vol. 25, pp. 617-689.

Zipf, R.K. (2006) Numerical modeling procedures for practical coal mine design, in Proceedings 41st U.S. Rock Mechanics Symposium, D.P. Yale, S.C. Holtz, C. Breeds and U. Ozbay (eds), 17-21 June 2006, Golden, USA, American Rock Mechanics Association, Alexandria, $11 \mathrm{p}$. 
